\title{
Self-Organization of PVD Cemented Carbide Tool When Cutting In718
}

\author{
Xinyu Song \\ School of Mechanical Engineering, \\ Weifang college, Weifang 261061, \\ China \\ sxy_100@163.com
}

\author{
Jun Zhao \\ School of Mechanical Engineering, \\ Shandong University, Jinan 250061, \\ China \\ Zhaojun@sdu.edu.cn
}

\author{
Yonghong Liu \\ School of Mechanical Engineering, \\ Weifang college, Weifang 261061, \\ China \\ liuyonghong1980@163.com
}

\begin{abstract}
Tool wear/tool life of PVD cemented coated carbide material in machining superalloy In718 has been studied by different methods. Self-organization theory is one of the effective ways to explain tool wear/tool life. In this paper, worn and fractured surfaces of the cutting tools were characterized by scanning electron microscopy (SEM) and energy dispersive X-ray spectroscopy (EDS). Self-organization of cutting tools during wear process was analyzed through SEM and EDS analysis. The results revealed that built-up edge and oxygen-containing surface film were two forms of tool self-organization in high speed turning of In718 with PVD cemented carbide inserts. Self-organization of the cutting tools took place with all kinds of wear mechanism during cutting. They affected the cutting tools in opposite directions with tool wear mechanisms, reducing the tool wear, protecting the loss of the tool materials effectively.
\end{abstract}

Keywords-PVD cemented carbide; Tool life; Nickel-based alloy; Self-organization

\section{INTRODUCTION}

Metal cutting is a complex phenomenon associated with a variety of different mechanical, physical and chemical processes which involve intensive plastic deformation of the workpiece ahead of the tool tip and severe frictional conditions at the interfaces of the tool, chip and the workpiece. Many researchers have used different methods to analyze this complex process. One of the achievements of modern methods is the development of the concept of self-organization, which deals with the complex processes on the basis of irreversible thermodynamics [1]. Self-organization is relevant to processes associated with the stability and degradation of structures that are formed under nonequilibrium conditions. Cutting processes are heavy load tribosystems which are irreversible thermodynamics. The analysis of stability and wear of the friction surface is critically needed for severe conditions associated with modern high-performance cutting operations [2]. During modern high-performance cutting, high pressure and extreme local temperatures can be encountered, especially during the cutting of hard to machine materials. Nickel-based superalloy In 718 is one kind of typical difficult-to-machine material [3] due to their high shear strength, work hardening tendency, highly abrasive carbide particles in the microstructure, strong tendency to weld [4] and low thermal conductivity [5] which has been widely applied for the parts in aerospace industry and nuclear reactor [6]. Studies of wear of cutting tools when machining In 718 have been carried out by different researchers. Chen and Liao [7] studied the wear mechanisms in drilling of In 718 with carbide tool; Li et al.,[8] studied the wear in milling of In 718 with carbide tool; Costes et al., [9] studied the wear mechanisms in turning of In 718 of CBN tools; Devillez et al [10] studied the wear in turning of In 718 with coated carbide tools. All these studies made detailed analysis of various tool failure mechanisms when cutting In 718. However, few published works studied the effect of self-organization to the tool wear. The purpose of this paper is to study comprehensively the tool wear and self-organization of TiAlN/TiN multilayer PVD cemented coated carbide cutting tools when tuning In 718.

\section{EXPERIMENT PROCEDURES}

Workpiece Material. The workpiece material used in this study was nickel-based superalloy In 718. which typically had a chemical composition as shown in Table 1 . The solid bars had a diameter of $80 \mathrm{~mm}$ and a length of $300 \mathrm{~mm}$. The hardness of the solid bars was $50 \mathrm{HRC}$.

TABLE 1 CHEMICAL COMPOSITION OF IN 718 (WT\%)

\begin{tabular}{|c|c|c|c|c|c|c|c|}
\hline $\mathrm{C}$ & $\mathrm{Mn}$ & $\mathrm{S} \mathrm{i}$ & $P$ & $\mathrm{~S}$ & $\mathrm{C} \mathrm{r}$ & A 1 & B \\
\hline 0.031 & 0.05 & 0.18 & 0.057 & 0.0055 & 19.16 & 0.58 & 0.0032 \\
\hline $\mathrm{Cu}$ & $\mathrm{Fe}$ & $\mathrm{Ni}$ & $\mathrm{Co}$ & Mo & $\mathrm{Ti}$ & $\mathrm{Nb}$ & \\
\hline 0.05 & bal & 51.50 & $<1.0$ & 3.07 & 0.97 & 5.06 & \\
\hline
\end{tabular}

This research is supported by Encouragement Foundation for Distinguished

Young Scientist of Shandong Province (BS2011ZZ019) and the National

Basic Research Program of China (2009CB724402) 
Cutting Tool. Cutting performance of two tool materials was tested in the experiment. The coated solid cemented carbide tool with $(\mathrm{Ti}, \mathrm{Al}) \mathrm{N}+\mathrm{TiN}$ coatings are physical vapor depositions (PVDs) coated on the substrate. Standard grade WC-Co with designation SNMG120408-MF1 (CP200 SECO Inc.) was used as the substrate. The tool inserts were mounted on a left-hand tool holder, PSSNR 2020K12. The tool geometries of the cutting inserts were listed in Table 2 .

TABLE 2 TOOL GEOMETRIES OF CUTTING TOOL

\begin{tabular}{|c|c|c|c|c|}
\hline$\gamma_{0}$ & $\alpha_{0}$ & $\mathrm{~K}_{\mathrm{r}}$ & $\lambda_{\mathrm{s}}$ & $\gamma_{\varepsilon}$ \\
\hline $4^{\circ}$ & $8^{\circ}$ & $45^{\circ}$ & $0^{\circ}$ & $0.8 \mathrm{~mm}$ \\
\hline
\end{tabular}

Machining Experiments. The machining tests were carried out using CA6140 lathe under dry conditions. Single factor experiment of cutting speed was done to examine the affect of cutting speed to tool wear. All the cutting parameters were shown in Table 3. Reference flank wear value $\mathrm{VB}=0.3 \mathrm{~mm}$ is chosen as wear criterion according to International Standard Organization (ISO 3685). Tool flank wear was measured at cutting intervals using microscopes. Wear photographs of tool inserts were taken using JSM-6380LA type scanning electron microscopes (SEM) equipped with an energy-dispersive X-ray spectrometer (EDS).

TABLE 3 CUTTING PARAMETERS

\begin{tabular}{|l|l|l|l|}
\hline Operations & $\begin{array}{l}\text { Cutting speed } \\
v(\mathrm{~m} / \mathrm{min})\end{array}$ & $\begin{array}{l}\text { Feed rate } \\
f(\mathrm{~mm} / \mathrm{r})\end{array}$ & $\begin{array}{l}\text { Depth of cut } \\
a_{\mathrm{p}}(\mathrm{mm})\end{array}$ \\
\hline $\begin{array}{l}\text { Single } \\
\text { factor } \\
\text { experiment }\end{array}$ & $50,70,90$ & 0.2 & 0.2 \\
\hline
\end{tabular}

\section{SELF-ORGANIZATION DURING CUTTING}

Self-organization of the cutting tools takes place with all kinds of wear mechanism during cutting. They affect the cutting tools in opposite directions. Tool wear mechanisms accelerate the tool wear, leading to the loss of the tool materials, while self-organization of the cutting tools reduce the tool wear, protecting the loss of the tool materials effectively. There are four tool self-organization forms when turning Nickel-base alloy In718 with PVD cemented carbide insert in high cutting speeds: built-up edge, flow zone, oxygen-containing surface film and adhesive layer.

Built-up Edge. In the low-speed conditions, BUE is a common wear patterns. Built-up edge appeared when cutting In 718 at the speed of $70 \mathrm{~m} / \mathrm{min}$ with PVD cemented carbide insert, as shown in Fig. 1. In such a cutting condition, shear stress of tool chip contact zone is strong which cause the workpiece material impact and seize on rake face of the tool, leaving a thin layer on the surface of the tool, further more, the matrix of nickel-based alloys In718 is austenite which causes rapid work hardening during machining. This provides the necessary conditions for the formation of the BUE. As a consequence of this work hardening, the thin layer of metal is stronger than the adjacent metal moving away from the workpiece. Effectively, the layer becomes part of the tool. The process repeats itself which causes the formation of the built up edge. The formation of BUE layer is considered to be the result of self-organization of the tool-workpiece tribosystem for the next two reasons: (1) The built-up layer is a dissipative structure or composite "third body," which consists of heavily deformed and refined machining material, as well as oxides, nitrides, and other compounds generated during cutting. The "ceramic-like" built-up layer offers significant protection to the tool surface; (2) On the other hand, the built-up edge reduce the rake angle of the cutting tool, the intensity of the tool cutting edge increased, the wear resistance of the tool is better.

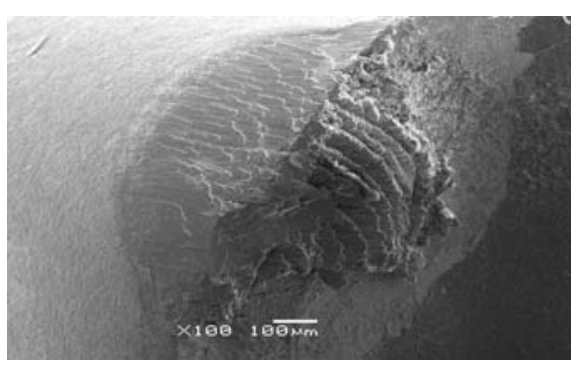

Fig. 1 SEM image of BUE $\left(v=70 \mathrm{~m} / \mathrm{min}, f=0.2 \mathrm{~mm} / \mathrm{r}, a_{\mathrm{p}}=0.2 \mathrm{~mm}\right)$

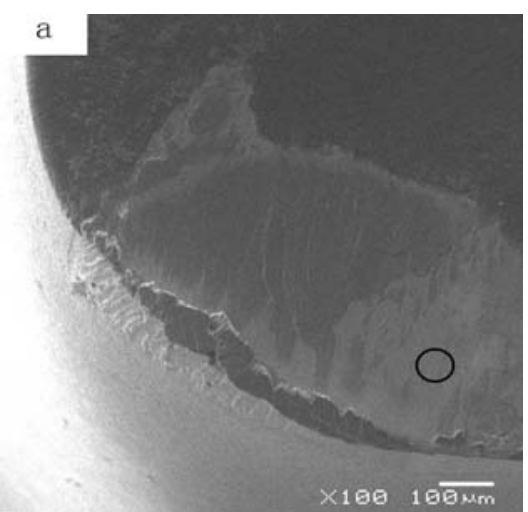

(a) Selected circular area on the rake face

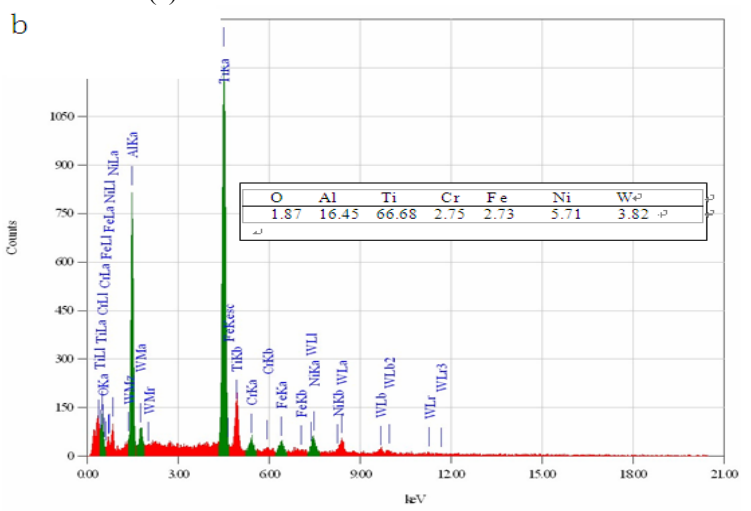

(b) EDS analysis

Fig. 2EDS analysis of the PVD inserts after machining $(v=70 \mathrm{~m} / \mathrm{min}, f=0.2$ $\mathrm{mm} / \mathrm{r}, a_{\mathrm{p}}=0.2 \mathrm{~mm}$ ) 
Oxygen-containing Surface Films. In high cutting speeds, the cutting temperature was high which provided a more suitable environment for oxidation reaction. Fig. 2 (b) showed the EDS analysis of the selected circular area marked on the rake face in Fig.2(a) when the cutting speed was $70 \mathrm{~m} / \mathrm{min}$. The element $\mathrm{O}$ was found in the material of the cutting tool which indicated that the oxidation was pronounced for the elements of tool material ( $\mathrm{Co} \mathrm{Ti}$ ) and oxygen in the air due to the high cutting temperature. A layer ( $\mathrm{Co} 2 \mathrm{O} 4, \mathrm{CoO}$ and $\mathrm{TiO} 2)$ with oxidized compounds is generated, as Fig. 2 (b) showed. The elastic modulus and hardness of the oxides were significantly lower than the matrix materials which played the role of solid lubricant, reducing the average friction coefficient, preventing occurrence of the diffusion and adhesion [11]. Therefore,the formation of energy-absorbing, oxygen-containing surface film can be considered to be an example of a cutting tool-workpiece self-organizing phenomenon. Furthermore, the oxygen-containing surface film avoids direct contact of tool-chip and tool-workpiece, thereby reducing tool wear.

\section{CONCLUSIONS}

Based on the experimental results, the effects of cutting speed on tool wear and self-organization to tool life were analyzed. The following conclusions can be deduced from the findings of this study.
(1) BUE were the result of self-organization on the rake face of the tool-workpiece tribosystem. When the cutting speed was $70 \mathrm{~m} / \mathrm{min}$, built-up layer offers significant protection to the tool surface.

(2) Oxygen-containing surface film and adhesive layer were another two self-organization forms of the PVD cemented carbide tools. They played important roles on self-organization of the cutting tool during cutting process. They led friction of the cutting process to a stabilization which decreased wear rate of the cutting tool, prolonged tool life.

\section{$\mathrm{V}$ REFERENCES}

[1] G S. Fox-Rabinovich and T. E. George, CRC Press, New York (2006).

[2] H. H. Synergetics, F.E.Plenum Press, New York. (1987).

[3] Jawaid, S. Koksal and S. Sharif, J. Mater. Process. Technol 116, 2(2001).

[4] N. Natural andY. Yamaha, Ann.CIRP 42, 103(1993).

[5] T. Kitagawa, A. Kubo and K. Maekawa, Wear 202, 142(1997).

[6] Y.S. Liao and R.H. Shiue, Wear 193, 16(1996).

[7] Y.C. Chen and Y.S. Liao, J. Mater. Process. Technol 140, 269 (2003).

[8] H.Z. Li, H. Zeng, and X.Q. Chen, J. Mater. Process. Technol 180, 296 (2006).

[9] J.P. Costes, Y. Guillet, and G. Poulachon, et al., Int. J. Mach. Tools Manuf 47, 1081 (2007).

[10] Devillez, F. Schneider and S. Dominiak, et al., Wear 262, 931( 2007).

[11] W. Konig and R. Fritsch, Surf. Coatings Technol. 49, 316 (1991). 